\title{
The Diurnal Rhythm of Bone Resorption in the Rat Effect of Feeding Habits and Pharmacological Inhibitors
}

\author{
Roman C. Mühlbauer and Herbert Fleisch \\ Department of Pathophysiology, University of Berne, CH-3010 Berne, Switzerland
}

\begin{abstract}
Prevention of low bone mass is important to reducing the incidence of osteoporotic fractures. This paper shows that, in rats, bone mass can be increased by feeding habits per se. Using six-hourly urinary excretion of $\left[{ }^{3} \mathrm{H}\right]$ tetracycline from prelabeled rats to monitor bone resorption, we previously found a peak of bone resorption following food administration. We now demonstrate that dividing the solid and liquid intake into portions blunts this peak and leads to a decrease in 24-h bone resorption to the level observed in thyroparathyroidectomized animals. Calcium balance increases and, when such feeding schedules are imposed for $30 \mathrm{~d}$, bone mass increases. Dividing the intake is not effective in thyroparathyroidectomized animals, indicating the importance of PTH and/or calcitonin. Administration of calcitonin inhibits practically only the peak of bone resorption, suggesting that it is osteoclast mediated. In contrast, treatment with a bisphosphonate reduces basal bone resorption without a specific effect on the peak, indicating a fundamentally different mechanism of action. This is also supported by the finding that their combined effects are additive. Whether bone mass in humans is also under the control of dietary habits is not known. If so, an increased meal frequency may be used to prevent osteoporosis. (J. Clin. Invest. 1995. 95:1933-1940.) Key words: parathyroid hormones • calcitonin $\cdot$ diphosphonates $\cdot$ bone disease $\bullet$ tetracyclines
\end{abstract}

\section{Introduction}

Bone mass in adult humans decreases with age, leading to an increase in the risk of fractures (1). With the longer life expectancy, fractures in the elderly have become a major health problem and will be even more so in the future. Prevention of low bone mass is therefore of prime importance. One of the means of reaching this goal is to increase the peak bone mass built up during adolescence. The other is to prevent the loss of bone in the elderly. Both can be approached either by increasing bone formation or by decreasing bone resorption. Fluoride is used

Part of this work was presented at the XIth International Conference on Calcium-Regulating Hormones, Florence, Italy, 24-29 April 1992, and has appeared in abstract form (1992. Bone Miner. 17 [Suppl. 1]:92).

Address correspondence to Roman C. Mühlbauer, Department of Pathophysiology, University of Berne, Murtenstrasse 35, CH-3010 Berne, Switzerland. FAX: 31-382-3038.

Received for publication 28 March 1994 and in revised form 12 December 1994.

J. Clin. Invest.

(C) The American Society for Clinical Investigation, Inc.

0021-9738/95/04/1933/08 \$2.00

Volume 95, April 1995, 1933-1940 currently, and PTH may possibly be used in this way in the future to increase formation. Estrogens, calcitonin, bisphosphonates, and calcium are used to decrease resorption $(2,3)$.

In the present study we have pursued another approach, namely, to influence the diurnal rhythm of bone resorption. For this purpose, we used a new technique that allows the continuous measurement of bone resorption (4). The technique is based on the chronic prelabeling of rats with $\left[7-{ }^{3} \mathrm{H}\right] \mathrm{N}$-tetracycline $\left(\left[{ }^{3} \mathrm{H}\right] \mathrm{TC}\right)^{1}(5)$. The measurement of $\left[{ }^{3} \mathrm{H}\right] \mathrm{TC}$ in the urine, after discontinuation of $\left[{ }^{3} \mathrm{H}\right] \mathrm{TC}$ injection, reflects bone resorption. When urine was collected every $6 \mathrm{~h}$, we found with this technique the existence of a pronounced diurnal rhythm of bone resorption (4). Since the rhythm was linked to food intake, with resorption increasing after food administration, the possibility of modulating it by changing the feeding habit of the animals arose.

In this paper we demonstrate that the diurnal rhythm of bone resorption is indeed blunted when the solid and liquid intake is divided into four portions instead of given at once. This is accompanied by a decrease in the 24-h excretion of $\left[{ }^{3} \mathrm{H}\right] \mathrm{TC}$ and an increased calcium balance as well as an increase in bone mass.

\section{Methods}

Animals. The experiments performed in this study were approved by the State Committee for the Control of Animal Experimentation. 2-moold male Wistar rats from our own colony were used. They were reared in standard animal facilities that comply with the U.S. National Institutes of Health and the Swiss guidelines for the care and use of laboratory animals. Until the experimental phase, the rats had free access to tap water and were fed ad lib. a standard laboratory chow (Kliba 331; Klingentalmühle, Kaiseraugst, Switzerland), containing $1.0 \mathrm{~g} \mathrm{Ca}, 0.7 \mathrm{~g}$ $\mathrm{P}$, and $80 \mathrm{IU}$ vitamin $\mathrm{D}_{3} / 100 \mathrm{~g}$ dry wt.

Labeling procedure. Starting 2-3d after birth, the rats were injected subcutaneously with a solution containing $10 \mu \mathrm{Ci} / \mathrm{ml}$ of $\left[{ }^{3} \mathrm{H}\right] \mathrm{TC}$ (New England Nuclear, Boston, MA) dissolved in $0.15 \mathrm{M} \mathrm{NaCl}$. As described previously (4), the injections were performed twice weekly for $6 \mathrm{wk}$, using increasing amounts of $\left[{ }^{3} \mathrm{H}\right] \mathrm{TC}$.

Maintenance during the experimentation. $1 \mathrm{wk}$ after the last $\left[{ }^{3} \mathrm{H}\right] \mathrm{TC}$ injection, i.e., at the age of $51 \mathrm{~d}$, the rats were housed in individual metabolic cages and switched from lab chow to a new diet in powder form. This basic diet had low $\mathrm{Ca}$ and phosphate contents (Sodi 2134; Klingentalmühle). Appropriate amounts of $\mathrm{Ca}$ gluconate and neutral phosphate salts were added, so that the final concentration was $1.1 \mathrm{~g}$ $\mathrm{Ca} / 100 \mathrm{~g}$ dry wt and $1.2 \mathrm{~g} \mathrm{P} / 100 \mathrm{~g}$ of dry wt of diet.

$28 \mathrm{~g}$ of wet food, corresponding to $15.8 \mathrm{~g}$ of dry matter, was provided daily, either as a single ball of $28 \mathrm{~g}$, which was put into the metabolic cage in a heavy glass cup, or as four aliquots of $7 \mathrm{~g}$, as indicated. The small portions were automatically delivered every $6 \mathrm{~h}$ by a feeding device.

1. Abbreviations used in this paper: $\left[{ }^{3} \mathrm{H}\right] \mathrm{TC},\left[7-{ }^{3} \mathrm{H}\right] N$-tetracycline; TPTX, thyroparathyroidectomy 


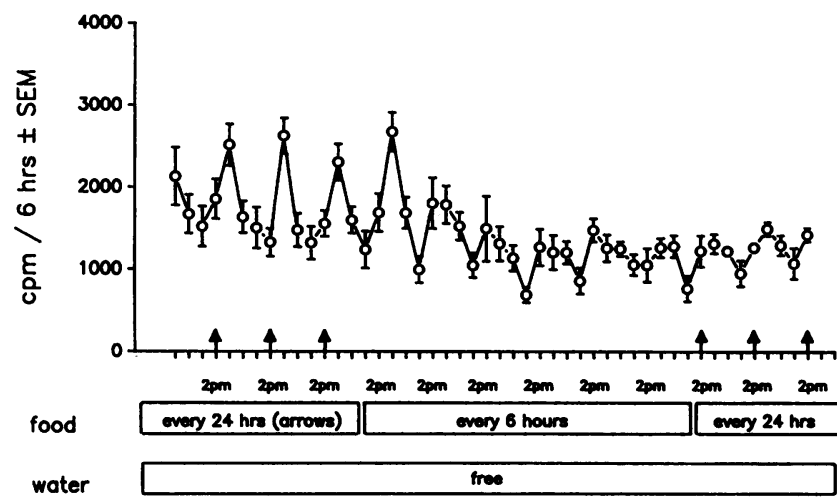

Figure 1. Effect of food fractionation on the diurnal rhythm of bone resorption. The daily intake of normal $\mathrm{Ca}$ diet was given either in one portion (arrows) or in four aliquots every $6 \mathrm{~h}$. Water was given once a day. $\left(n=6 ; \mathrm{cpm}={ }^{3} \mathrm{H} \mathrm{cpm}\right.$ in urine)

The amount of food given was slightly less than the quantity the rats would eat spontaneously, so that all animals ate the entire amount of food offered. Except in the experiment investigating the effect of water fractionation (see Fig. 2 and Table II), all rats consumed their food portions within $2 \mathrm{~h}$. Demineralized water was available either freely or as $5-\mathrm{ml}$ aliquots every $6 \mathrm{~h}$. The daily intake of water was measured and verified by the urine volume.

Urine collection. After $10 \mathrm{~d}$ of adaptation to the individual metabolic cages, 24-h urine collections were performed, either manually once a day at the same time or every $6 \mathrm{~h}$, as described previously (4).

Thyroparathyroidectomy (TPTX). TPTX was performed surgically under ether anesthesia. Plasma Ca concentration of $<2 \mathrm{mml} /$ liter served as criterion of successful TPTX. Blood samples were obtained after an overnight fast $3 \mathrm{~d}$ after completion of the experiment from anesthetized animals by retroorbital puncture with microhematocrit capillaries.

Injections. Synthetic salmon calcitonin (Miacalcic ; Sandoz AG, Basel, Switzerland) was injected subcutaneously once daily during 3 or $4 \mathrm{~d}$ as indicated, either at the doses of $1.25 \mathrm{IU} / \mathrm{kg}, 1.875 \mathrm{IU} / \mathrm{kg}$, or 2.5 IU/kg body wt. It was diluted with a solvent consisting of $0.1 \mathrm{M}$ sodium acetate containing $167 \mu \mathrm{l} / \mathrm{ml}$ heat-inactivated rat plasma. Control animals received the same volume $(1 \mathrm{ml} / \mathrm{kg}$ body wt) of solvent.

Alendronate, i.e., (4-amino-1-hydroxybutylidene)bis-phosphonate, was administered subcutaneously as a single injection of $0.1 \mathrm{mg} \mathrm{P} / \mathrm{kg}$ body wt. The control rats received the same volume $(2 \mathrm{ml} / \mathrm{kg}$ body $\mathrm{wt}$ ) of $0.15 \mathrm{M} \mathrm{NaCl}$. In a further experiment, the effect of calcitonin at a dose of $2.5 \mathrm{IU} / \mathrm{kg}$ body wt was investigated in rats pretreated $3 \mathrm{~d}$ before with alendronate at the same dose

Etidronate, i.e., (1-hydroxyethylidene)bis-phosphonate, was injected once a day for $8 \mathrm{~d}$ at the dose of $10 \mathrm{mg} \mathrm{P} / \mathrm{kg}$ body wt. The control rats received the same volume $(2 \mathrm{ml} / \mathrm{kg}$ body wt) of $0.15 \mathrm{M}$ $\mathrm{NaCl}$. At death, the occurrence of rickets was verified radiographically.

Assessment of physical activity. The physical activity of the animals subjected to both dietary regimens ( $n=6$ for each dietary group) was recorded with a video camera. To allow recordings during the dark period $(12 \mathrm{~h})$, the room was illuminated with a weak source of red light (two darkroom bulbs directed towards the ceiling) throughout the experiment. Two adjacent cages (one for each dietary group) were filmed simultaneously with a highly sensitive red light camera for 3 min every $2 \mathrm{~h}$ for $24 \mathrm{~h}$. Thus, after $6 \mathrm{~d}$, a total of $36 \mathrm{~min}$ of behavior was recorded on video tape for each rat. These tapes were then evaluated using ethopharmacologically defined elements of nonsocial behavior, i.e., muscularly demanding activity such as the cumulative frequency of horizontal activity (elements explore and substrate), vertical activity (elements rear and scan), body care (elements scratch, self groom, wash), and ingestive behavior (elements drink and eat), as well as the cumulative immobility time (elements sit and sleep) $(6,7)$.

Analytical procedures. ${ }^{3} \mathrm{H}$ in urine was determined by liquid scintil-

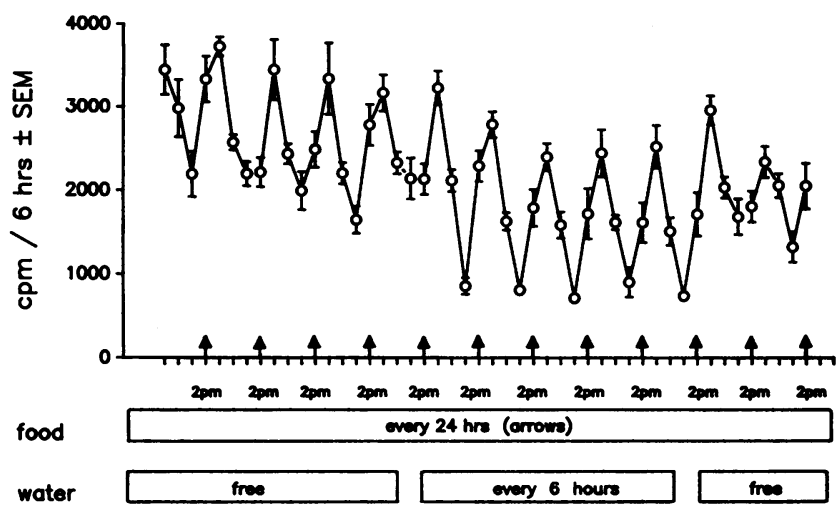

Figure 2. Effect of fractionating the liquid intake on the diurnal rhythm of bone resorption. The daily intake of demineralized water was provided either in a water bottle (free access) or as 5 -ml aliquots every 6 h. Food was given once a day. $\left(n=6 ; \mathrm{cpm}={ }^{3} \mathrm{H} \mathrm{cpm}\right.$ in urine)

lation counting. Aliquots of $1 \mathrm{ml}$ urine were counted in $10 \mathrm{ml}$ of Ultima Gold ${ }^{\star}$ scintillator (Packard International, Zurich, Switzerland), and the result was multiplied by the urine volume. Since quenching was similar between samples, the data are reported as counts per minute.

Calcium in the diets and bones was determined by atomic absorption spectrophotometry in ashed samples dissolved with $1 \mathrm{~N} \mathrm{HCl}$. In one experiment the whole carcass calcium was also determined. After removal of the left tibia for histological examination, the whole bodies were skinned and eviscerated, and the soft tissues were removed by dermestid beetles $(8)$. The right tibia was ashed separately from the rest of the skeleton. Whole body calcium was calculated from the concentration found in the remainder of the carcass and the concentration of calcium measured in the right tibia $\times 2$.

For the morphological evaluation of bone mass, the trabecular bone volume was measured in $6-\mu \mathrm{m}$-thick metacrylate sections of the metaphysis of the left tibia stained with the von Kossa reaction. Trabeculae (stained black) were counted in the area $1 \mathrm{~mm}$ below the epiphyseal cartilage and are expressed in percentage of the total area measured (9).

Data presentation. Results are given as mean values \pm SEM. The significance of differences between groups was evaluated by Student's $t$ test.

\section{Results}

EFFECT OF FEEDING HABITS

As previously shown, a diurnal rhythm of bone resorption occurs in rats with a peak after access to food (Figs. 1-3).

To investigate the influence of the quantity of food given in one portion on this diurnal rhythm, rats were provided with the same daily amount of food of identical composition in four portions instead of one. When the animals were fed every $6 \mathrm{~h}$ and water was freely available, the resorption peaks of the diurnal rhythm were reduced as compared to the baseline measurement when food was given once a day (Fig. 1).

When water was given in aliquots every $6 \mathrm{~h}$ and food once a day, the resorption peaks were not diminished, but the nadir values between the peaks decreased as compared to the baseline values (Fig. 2). When water was again freely available, the diurnal rhythm resumed baseline values.

Dividing both food and water into 6-h portions decreased the diurnal rhythm of bone resorption slightly more (Fig. 3) than food portioning had done (Fig. 1). The return to basal feeding conditions led to a partial recovery. 


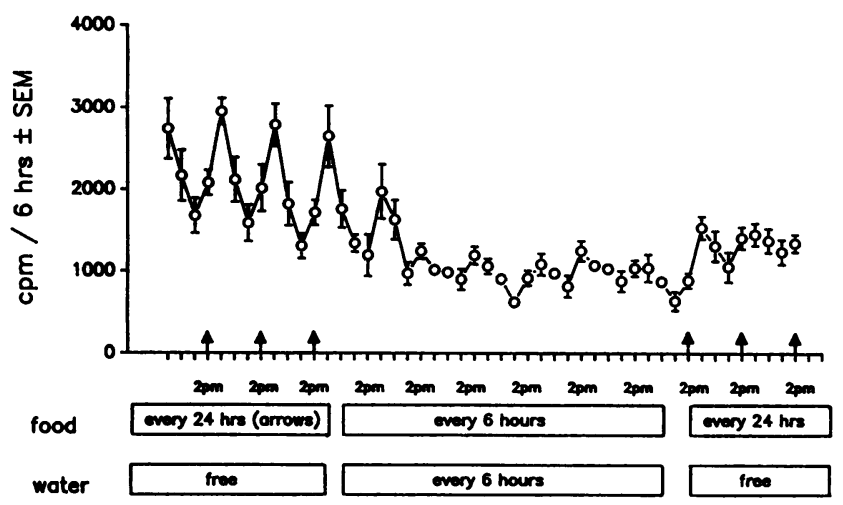

Figure 3. Effect of fractionating both the solid and liquid intake on the diurnal rhythm of bone resorption. Food was provided as described in the legend to Fig. 1, and water as in the legend to Fig. 2. ( $n=6$; cpm $={ }^{3} \mathrm{H} \mathrm{cpm}$ in urine)

The animals receiving food every $6 \mathrm{~h}$ had a tendency to change their drinking habits. Instead of drinking almost the entire volume at the usual feeding time of 2:00 p.m., they distributed to some extent their fluid intake over the whole day. Therefore, to assess the effect of food fractionation, only two groups, both receiving water every $6 \mathrm{~h}$ but one being fed every $6 \mathrm{~h}$ (treated) and the other every $24 \mathrm{~h}$ (control), were compared. To assess the magnitude of the overall daily inhibition of bone resorption, the values from the four six-hourly urines collected each day were pooled, and results were given as $24 \mathrm{~h}\left[{ }^{3} \mathrm{H}\right] \mathrm{TC}$ excretion. As shown in Table I, food portioning alone led to an inhibition of bone resorption of $20-25 \%$. Table I also shows that the onset as well as the disappearance of this effect occurs after a time lag of $1 \mathrm{~d}$.

Rats that were given the water in portions every $6 \mathrm{~h}$ tended to take more than the usual time to consume their food portions. To assess precisely the effect of portioning water alone, the same strategy was used as that described for food, with all animals being fed every $6 \mathrm{~h}$. In the treated group, water was also given every $6 \mathrm{~h}$, while in the control group water was freely available. The data, expressed as treated/control of cumulative 24-h $\left[{ }^{3} \mathrm{H}\right] \mathrm{TC}$ excretion, show that the fractionation of water intake leads to an inhibition of bone resorption of $\sim 20$ 25\%. (Table II). This effect occurs without a time lag.

Finally, as shown in Table III, food and water fractionation as compared to food and water given once a day also inhibited bone resorption by about $20-25 \%$.

We also investigated whether food fractionation affects physical activity. The cumulative frequency of horizontal activity was $45.2 \pm 10.5$ vs $25.2 \pm 8.3$; the vertical activity was $23.7 \pm 20.3$ vs $16.5 \pm 11.6$; the body care activity was $28.6 \pm 7.0$ vs 17.8 \pm 6.0 ; and the frequency of ingestive behavior was $9.2 \pm 5.2$ vs $4.1 \pm 1.8$ for rats receiving their daily solid and liquid intake once a day vs every $6 \mathrm{~h}$. Furthermore, the cumulative immobility time was $538.4 \pm 113.9 \mathrm{~s}$ vs $474.2 \pm 120.0 \mathrm{~s}$ for rats fed once vs four times per day, observed for $2,160 \mathrm{~s}$ each. The tendency for lower values in the rats with fractionated intake did not reach significance level. To assess whether the red light illumination at night influenced bone resorption and/or the effect of the dietary manipulation, $\left[{ }^{3} \mathrm{H}\right] \mathrm{TC}$ urinary excretion was monitored in the same animals. An unchanged diurnal rhythm was found in controls, and the inhibition of bone resorption by food fractionation was also confirmed (data not shown). The time of recording covered most of the eating period in the rats on the fractionated schedule, while a large part of the eating period remained undocumented in the others. To avoid a possible bias, the results were also calculated excluding the eating periods. Again, all values reflecting physical activity were lower in the animals on fractionated intake, and no values reached a significance level. After exclusion of the eating periods, the cumulative immobility time increased to $584.4 \pm 114.1 \mathrm{~s}$ vs $699.4 \pm 110.3 \mathrm{~s}$ for rats on one portion vs four portions a day.

Calcium balances over $3 \mathrm{~d}$ were then performed to establish whether the decrease in bone resorption was accompanied by an increase in body calcium retention. A first balance was performed when the rats received food and water once a day, the second from day 2 after starting the food and water fractionation

Table I. Effect of Food Fractionation on Cumulative 24-h Urinary $\left[{ }^{3} H\right] T C$ Excretion

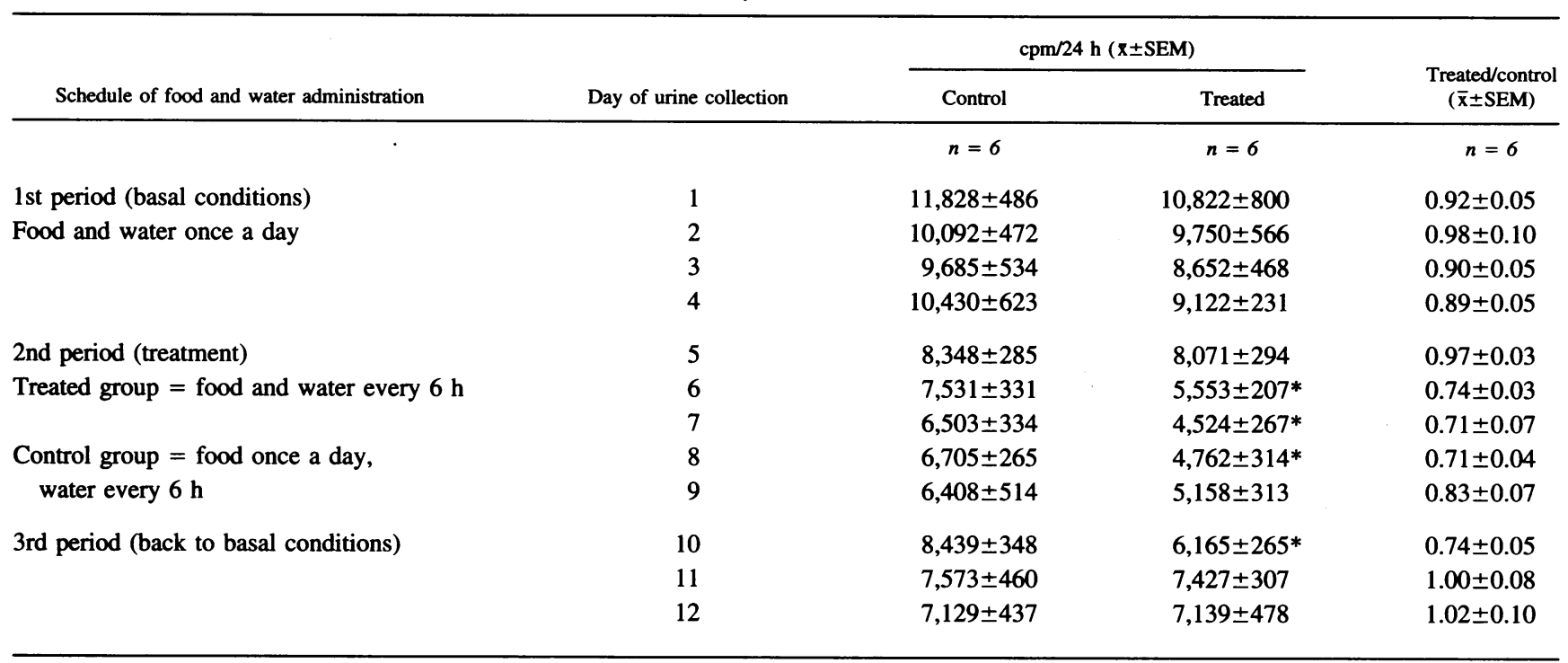

* Significant difference from control $(P<0.001)$. 
Table II. Effect of Water Fractionation on Cumulative 24 h Urinary $\left[{ }^{3} H\right] T C$ Excretion

\begin{tabular}{|c|c|c|c|c|}
\hline \multirow[b]{2}{*}{ Schedule of food and water administration } & \multirow[b]{2}{*}{ Day of urine collection } & \multicolumn{2}{|c|}{$\mathrm{cpm} / 24 \mathrm{~h}(\mathrm{x} \pm \mathrm{SEM})$} & \multirow{2}{*}{$\begin{array}{c}\text { Treated/control } \\
(\overline{\mathbf{x}} \pm \text { SEM) }\end{array}$} \\
\hline & & Control & Treated & \\
\hline & & $n=5$ & $n=5$ & $n=5$ \\
\hline 1st period (basal conditions) & 1 & $8,071 \pm 685$ & $8,427 \pm 493$ & $1.06 \pm 2.1$ \\
\hline \multirow[t]{2}{*}{ Food and water once a day } & 2 & $7,269 \pm 466$ & $7,755 \pm 437$ & $1.08 \pm 0.06$ \\
\hline & 3 & $7,105 \pm 648$ & $7,126 \pm 549$ & $1.03 \pm 0.11$ \\
\hline 2nd period (treatment) & 4 & $7,635 \pm 496$ & $5,582 \pm 338 *$ & $0.74 \pm 0.06$ \\
\hline \multirow[t]{2}{*}{ Treated group $=$ food and water every $6 \mathrm{~h}$} & 5 & $6,724 \pm 581$ & $4,016 \pm 138^{\ddagger}$ & $0.62 \pm 0.05$ \\
\hline & 6 & $5,020 \pm 745$ & $3,823 \pm 96$ & $0.81 \pm 0.09$ \\
\hline \multirow{3}{*}{$\begin{array}{l}\text { Control group }=\text { water once a day, } \\
\text { food every } 6 \mathrm{~h}\end{array}$} & 7 & $4,845 \pm 717$ & $3,854 \pm 134$ & $0.84 \pm 0.09$ \\
\hline & 8 & $5,283 \pm 381$ & $4,199 \pm 319$ & $0.80 \pm 0.04$ \\
\hline & 9 & $4,619 \pm 497$ & $3,406 \pm 294$ & $0.75 \pm 0.06$ \\
\hline \multirow[t]{3}{*}{ 3rd period (back to basal conditions) } & 10 & $4,967 \pm 149$ & $4,448 \pm 426$ & $0.90 \pm 0.9$ \\
\hline & 11 & $5,372 \pm 286$ & $5,076 \pm 302$ & $0.95 \pm 0.06$ \\
\hline & 12 & $5,674 \pm 152$ & $5,290 \pm 508$ & $0.93 \pm 0.09$ \\
\hline
\end{tabular}

* Significant difference from control $(p<0.001) ;{ }^{\ddagger}$ significant difference from control $(p<0.01)$.

feeding regimen (Table IV). The calcium balance increased by $6.81 \pm 2.67 \mathrm{mg} / \mathrm{d}$, mainly because of an increase of the net intestinal $\mathrm{Ca}$ absorption.

To investigate whether this effect was caused by an increase of circulating $1,25(\mathrm{OH})_{2} \mathrm{D}_{3}$, the concentration of this hormone was measured in plasma at the end of a 3-d feeding period. $1,25(\mathrm{OH})_{2} \mathrm{D}_{3}$ did not increase but, if anything, decreased slightly from $103.8 \pm 15.9 \mathrm{pmol} / \mathrm{liter}(n=5)$ in animals receiving water and food once a day, to $88.0 \pm 22.7 \mathrm{pmol} / \mathrm{liter}(n=6)$ in rats receiving their daily intake of food and water in portions. This difference is, however, not significant, and both values were within the range of normal values (96 443 [SD] pmol/ liter, $n=22$ ) of our laboratory for intact rats fed a normal calcium diet.

To investigate whether the increase in calcium balance was only a transient phenomenon, groups of 1-mo-old intact rats without $\left[{ }^{3} \mathrm{H}\right] \mathrm{TC}$ prelabeling were given food and water every $6 \mathrm{~h}$ for $30 \mathrm{~d}$; the controls received the same amount of food and water of identical composition once every $24 \mathrm{~h}$. A conspicuous increase in whole body calcium as well as in trabecular bone volume was found, confirming the balance data (Table V).

MECHANISM(S) OF BLUNTING BONE RESORPTION BY FEEDING HABITS

\section{Effect of TPTX}

We have previously shown that TPTX decreased $\left[{ }^{3} \mathrm{H}\right] \mathrm{TC}$ excretion by $30-40 \%$. In this condition, a diurnal rhythm of bone resorption persisted, but its amplitude decreased in proportion to the basal bone resorption, so that an unchanged fractional rhythm was observed as compared to sham-operated animals (4). The question of whether the presence of the thyroparathyroid glands is a prerequisite for the effect of food fractionation on bone resorption was investigated in TPTX rats. Fig. 4 confirms the diurnal rhythm of bone resorption in TPTX rats given food once a day found earlier. However, in contrast to results among intact rats, providing food and water in portions every $6 \mathrm{~h}$ did not affect this rhythm of urinary $\left[{ }^{3} \mathrm{H}\right] \mathrm{TC}$ excretion.

Table III. Effect of Food and Water Fractionation on 24-h Urinary $\left[^{3} \mathrm{H}\right] \mathrm{TC}$ Excretion

\begin{tabular}{|c|c|c|c|c|}
\hline \multirow[b]{2}{*}{ Schedule of food and water administration } & \multirow[b]{2}{*}{ Day of urine collection } & \multicolumn{2}{|c|}{$\mathrm{cpm} / 24 \mathrm{~h}(\mathrm{x} \pm \mathrm{SEM})$} & \multirow{2}{*}{$\begin{array}{c}\text { Treated/control } \\
(\overline{\mathbf{x}} \pm \text { SEM) }\end{array}$} \\
\hline & & Control & Treated & \\
\hline & & $n=5$ & $n=6$ & $n=6$ \\
\hline 1st period (basal conditions) & 1 & $6,044 \pm 379$ & $6,002 \pm 462$ & $1.05 \pm 0.11$ \\
\hline \multirow[t]{2}{*}{ Food and water once a day } & 2 & $5,629 \pm 339$ & $5,688 \pm 208$ & $1.02 \pm 0.06$ \\
\hline & 3 & $5,585 \pm 361$ & $5,341 \pm 220$ & $1.01 \pm 0.10$ \\
\hline 2nd period (treatment) & 4 & $5,544 \pm 392$ & $4,197 \pm 184^{*}$ & $0.78 \pm 0.07$ \\
\hline \multirow[t]{2}{*}{ Treated group $=$ food and water every $6 h$} & 5 & $5,358 \pm 266$ & $4,408 \pm 245^{\ddagger}$ & $0.85 \pm 0.04$ \\
\hline & 6 & $4,602 \pm 284$ & $3,697 \pm 213^{\ddagger}$ & $0.83 \pm 0.10$ \\
\hline \multirow[t]{2}{*}{ Control group $=$ food and water once a day } & 7 & $4,980 \pm 90$ & $3,527 \pm 156^{8}$ & $0.72 \pm 0.05$ \\
\hline & 8 & $4,585 \pm 300$ & $3,634 \pm 201^{\ddagger}$ & $0.81 \pm 0.09$ \\
\hline
\end{tabular}

\footnotetext{
* Significant difference from control $(p<0.01) ;{ }^{\ddagger}$ significant difference from control $(p<0.05) ;{ }^{8}$ significant difference from control $(p<0.001)$.
} 
Table IV. Effect of Food and Water Fractionation on Calcium Balance

\begin{tabular}{lcc}
\hline & \multicolumn{2}{c}{ Feeding regimen } \\
\cline { 2 - 3 } & $\begin{array}{c}\text { Food and water } \\
\text { once a day }\end{array}$ & $\begin{array}{c}\text { Food and water } \\
\text { every } 6 \mathrm{~h}\end{array}$ \\
\hline & $n=12$ & $n=12$ \\
Calcium intake (mg/d) & $172.79 \pm 0.17$ & $171.8 \pm 0.22$ \\
Fecal calcium excretion $(\mathrm{mg} / \mathrm{d})$ & $139.00 \pm 2.35$ & $132.16 \pm 2.12$ \\
Urinary calcium excretion $(\mathrm{mg} / \mathrm{d})$ & $3.12 \pm 0.32$ & $2.19 \pm 0.47$ \\
Net calcium absorption $(\mathrm{mg} / \mathrm{d})$ & $33.76 \pm 2.30$ & $39.39 \pm 1.85$ \\
$\begin{array}{l}\text { Calcium balance }(\text { net calcium } \\
\quad \text { retention; } \mathrm{mg} / \mathrm{d})\end{array}$ & $30.64 \pm 2.23$ & $37.46 \pm 2.11^{*}$
\end{tabular}

* Significant difference $(p<0.05)$.

Interestingly, the diurnal rhythm of bone resorption of rats with intact thyroparathyroid glands quickly became similar to the one observed in TPTX rats upon food and water portioning.

\section{Effect of calcitonin and bisphosphonate}

Fig. $5 a$ shows that a dose of $2.5 \mathrm{IU} / \mathrm{kg}$ body wt of calcitonin, administered $6 \mathrm{~h}$ before feeding time, abolishes the postprandial increase of bone resorption. This effect was much smaller when the drug was given just before the daily feeding, i.e., at 2:00 p.m. (Fig. $5 \mathrm{~b}$ ). Therefore, the optimal time of administration was investigated with a dose of $1.25 \mathrm{IU} / \mathrm{kg}$ body wt of calcitonin injected at 8:00 a.m., 11:00 a.m., and 2:00 p.m. The maximal effect appeared at 11:00 a.m. (data not shown). Thus, in the subsequent experiments, calcitonin was always administered 3 $\mathrm{h}$ before feeding. Fig. 6, $a-c$ shows the dose-dependent inhibition of the diurnal rhythm of bone resorption by calcitonin. The inhibition occurs clearly after the first injection, and a full recovery is observed $24 \mathrm{~h}$ after the last injection. While just the peak height is diminished at the low dose of $1.25 \mathrm{IU} / \mathrm{kg}$ body wt (Fig. $6 a$ ), calcitonin at higher doses tends to lower the nadir values also.

As previously shown, in spite of a $60 \%$ inhibition of bone resorption with the bisphosphonate alendronate, the diurnal rhythm persisted (4). To investigate whether the effects of calcitonin were additive, animals were given both inhibitors. Fig. 7 $a$ confirms that, $3 \mathrm{~d}$ after a single injection of alendronate at a dose of $0.1 \mathrm{mg} \mathrm{P} / \mathrm{kg}$ body wt, bone resorption was strongly and persistently inhibited. The diurnal rhythm was preserved at a proportioned level. In Fig. $7 b$, all animals were pretreated with

Table V. Influence of Feeding Frequency on Calcium Content in the Skeleton and on Trabecular Bone Volume

\begin{tabular}{ccccc}
\hline & & \multicolumn{2}{c}{ After $30 \mathrm{~d}$ of treatment } \\
\cline { 3 - 5 } $\begin{array}{c}\text { Treatment } \\
\text { (feeding frequency) }\end{array}$ & Initial body wt & $n$ & Total body Ca & $\begin{array}{r}\text { Trabecular } \\
\text { bone volume }\end{array}$ \\
\hline & $g \pm S E M$ & & $m g \pm S E M$ & Percent \pm SEM \\
$1 \times$ daily & $97.3 \pm 4.4$ & 6 & $1,287.6 \pm 60.7$ & $32.3 \pm 1.03$ \\
$4 \times$ daily & $95.5 \pm 2.2$ & 6 & $1,493.0^{*} \pm 62.7$ & $38.4^{*} \pm 1.93$
\end{tabular}

* Significant difference between the two groups $(p<0.05)$.

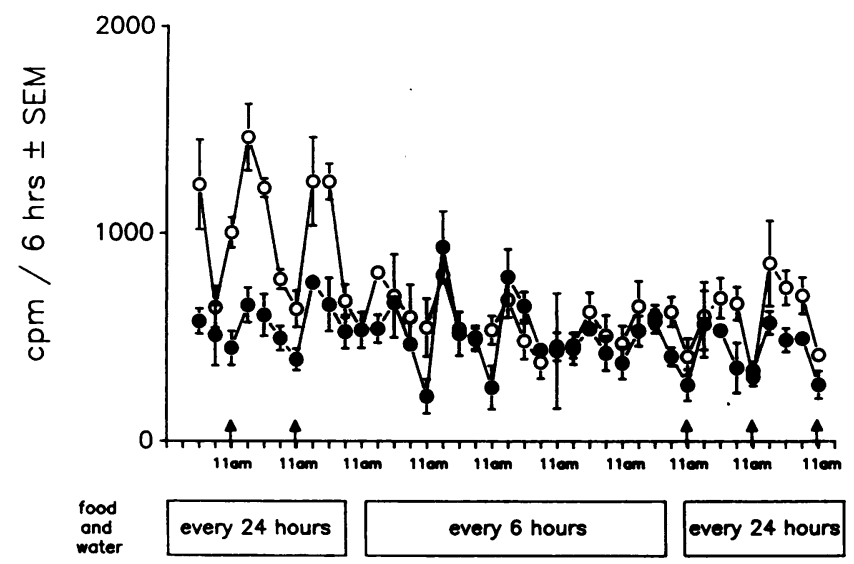

Figure 4. Comparison of the effect of food and water fractionation on the diurnal rhythm of bone resorption (see legends to Figs. 1 and 2 ) in sham-operated $(\mathrm{O}-\mathrm{O})$ and TPTX $(\bullet-\bullet)$ rats. $(n=4$ each in group; cpm $={ }^{3} \mathrm{H} \mathrm{cpm}$ in urine)

the bisphosphonate. Under these conditions, calcitonin virtually abolished the increase of bone resorption occurring after food administration without a substantial effect on the basal bone resorption. The effect of calcitonin was again rapid, and reversible after discontinuation of the treatment.

Effect of inhibition of bone mineralization on the diurnal rhythm of bone resorption

To investigate whether "bone formation," i.e., the calcium requirement for mineralization, would represent a trigger for the
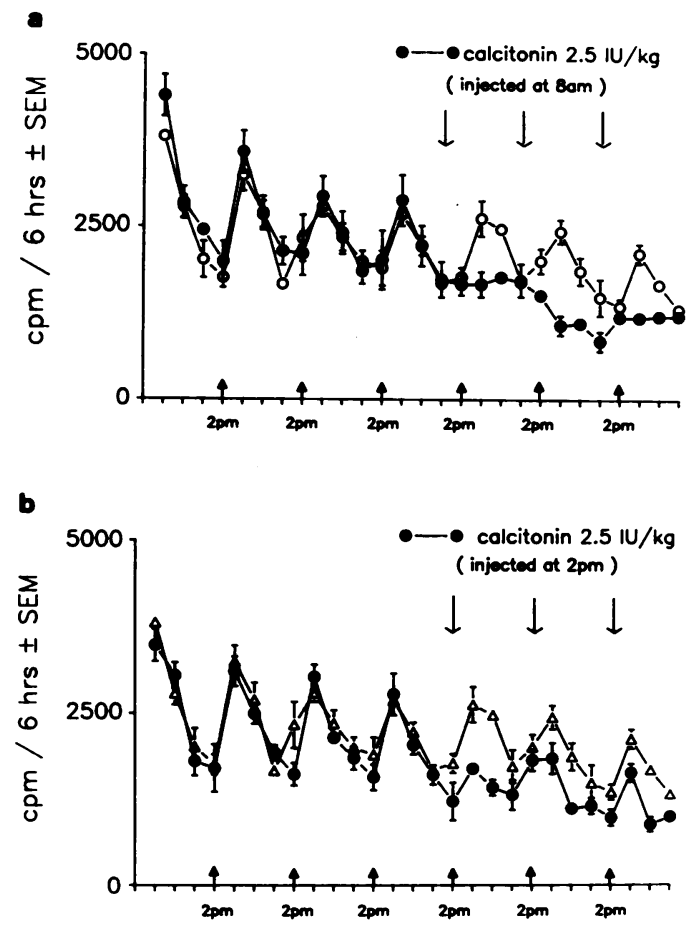

Figure 5. Time course of the inhibitory effect of calcitonin on the diurnal rhythm of bone resorption. $(a) \circ-\circ$, controls injected with solvent; $-\bullet, 2.5 \mathrm{IU} / \mathrm{kg}$ of calcitonin injected $6 \mathrm{~h}$ before feeding (thin arrows). ( $n=4$ in each group) $(b) \circ-0$, controls; $\bullet-\bullet, 2.5$ $\mathrm{IU} / \mathrm{kg}$ of calcitonin injected just before feeding (thin arrows). $(n=4$ in each group; $\mathrm{cpm}={ }^{3} \mathrm{H} \mathrm{cpm}$ in urine) 


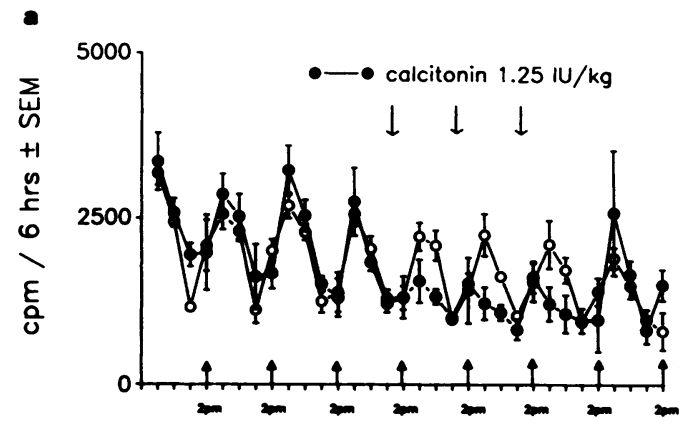

b
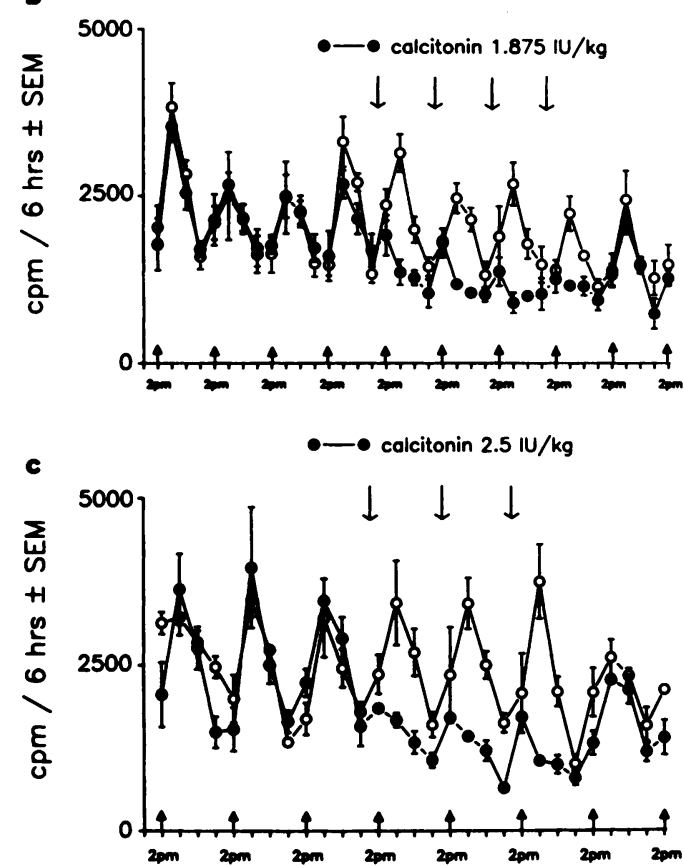

Figure 6. Dose response of the inhibitory effect of calcitonin, injected $3 \mathrm{~h}$ before feeding, on the diurnal rhythm of bone resorption. (a) $\circ-\bigcirc$, controls; $\bullet-\bullet, 1.25 \mathrm{IU} / \mathrm{kg}$ of calcitonin (thin arrows). ( $n=3$ in each group) $(b) \circ-\circ$, controls; $\bullet-\bullet, 1.875 \mathrm{IU} / \mathrm{kg}$ of calcitonin (thin arrows). ( $n=3$ in each group) (c) $\bigcirc-\bigcirc$, controls; $\bullet-\bullet, 2.5 \mathrm{IU} / \mathrm{kg}$ of calcitonin (thin arrows). $(n=3$ in each group; cpm $={ }^{3} \mathrm{H} \mathrm{cpm}$ in urine)

increase of bone resorption observed after food administration, rats were treated with the bisphosphonate etidronate at a rachitogenic dose. Fig. $8 a$ shows the inhibitory effect of etidronate on bone resorption as assessed with 24 -h urinary $\left[{ }^{3} \mathrm{H}\right] \mathrm{TC}$ excretion. $X$ rays taken at the end of the urine collections (not shown) indicated, as expected, an inhibition of mineralization, i.e., a conspicuous widening of the epiphyseal line. However, the fractional diurnal rhythm of bone resorption expressed in percentage of the 24-h urinary [ ${ }^{3} \mathrm{H}$ ]TC excretion, assessed during the last $6 \mathrm{~d}$ of treatment, was unaltered (Fig. $8 b$ ).

\section{Discussion}

The present results confirm the existence of a strong diurnal rhythm of $\left[{ }^{3} \mathrm{H}\right] \mathrm{TC}$ urinary excretion in the rat and document how it can be influenced by dietary and pharmacological means. We have previously shown, using three known means of in- a

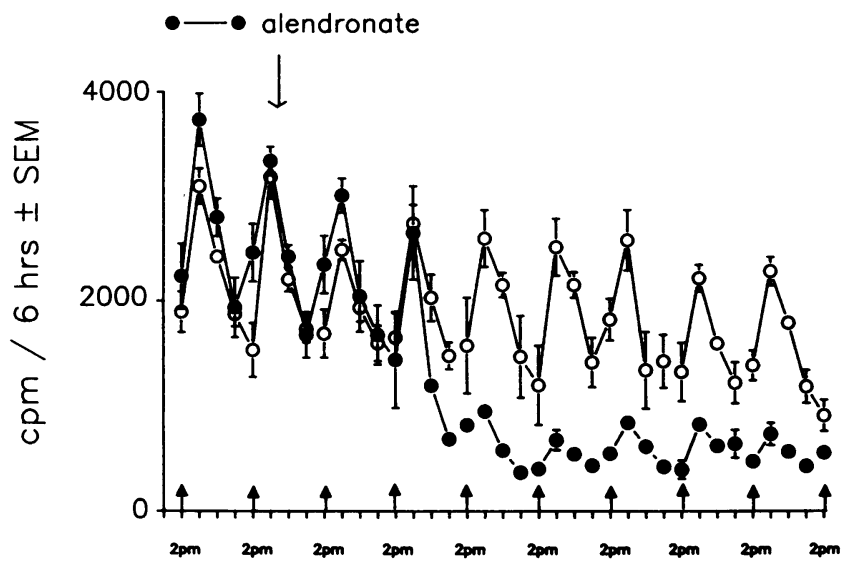

b

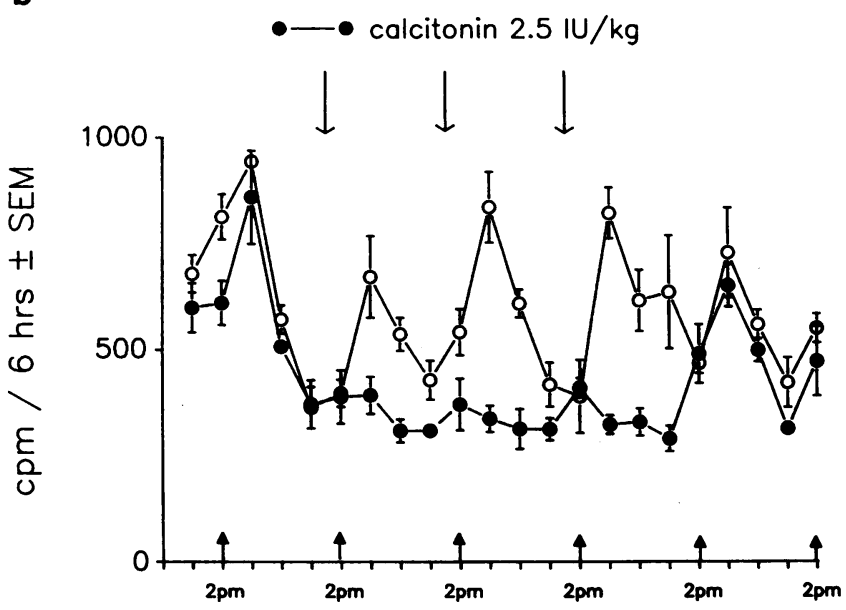

Figure 7. Additive effect of calcitonin and the bisphosphonate alendronate on the diurnal rhythm of bone resorption. $(a) \circ-\circ$, controls injected with saline; $\bullet-\bullet$, one injection (thin arrow) $0.1 \mathrm{mg} \mathrm{P} / \mathrm{kg}$ of alendronate. ( $n=4$ in each group) (b) $\bigcirc-\circ$, rats of panel $a$ starting on day 3 after alendronate injection; $\bullet-\bullet$, rats injected with alendronate and $2.5 \mathrm{IU} / \mathrm{kg}$ of calcitonin at the indicated time (thin arrows $)$. ( $n=4$ in each group; $\mathrm{cpm}={ }^{3} \mathrm{H} \mathrm{cpm}$ in urine $)$

creasing and decreasing bone resorption, that the excretion of [ ${ }^{3} \mathrm{H}$ ] TC over $24 \mathrm{~h}$ reflects bone resorption (4). This is because the $\left[{ }^{3} \mathrm{H}\right] \mathrm{TC}$ released from bone during bone resorption is only poorly reincorporated into newly formed bone, most probably because it circulates in a form that binds poorly to hydroxyapatite and is efficiently excreted by the kidney (4). Furthermore, the method we have validated uses the mass of $\left[{ }^{3} \mathrm{H}\right] \mathrm{TC}$ excreted in the urine per unit of time. Therefore, it takes advantage of the fact that, even if the glomerular filtration rate changes during an experimental maneuver, by virtue of the opposite change in the $\left[{ }^{3} \mathrm{H}\right] \mathrm{TC}$ plasma concentration, the filtered load and therefore the urinary excretion of $\left[{ }^{3} \mathrm{H}\right] \mathrm{TC}$ will remain constant $(10)$. Thus, the $\left[{ }^{3} \mathrm{H}\right] \mathrm{TC}$ technique allows the monitoring of bone resorption at six-hourly intervals.

Previous results have also shown that the diurnal rhythm of bone resorption was the consequence of food intake leading to an increase of bone resorption. This paper shows that providing the daily solid and liquid intake in four portions instead of in one not only blunts this daily rhythm but also diminishes the 


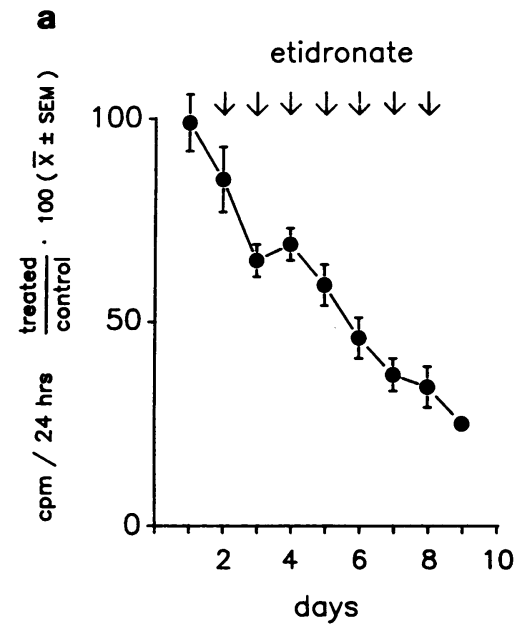

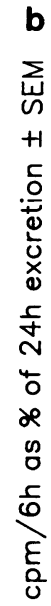

Figure 8. Effect of rachitogenic doses (seven injections) of $10 \mathrm{mg}$ $\mathrm{P} / \mathrm{kg}$ of etidronate (thin arrows) on: (a) 24-h bone resorption given as treated/control. ( $n=6$ each for control and treated) $(b)$ fractional daily rhythm of bone resorption. $\mathrm{O} \longrightarrow \mathrm{O}$, controls; $\bullet-\bullet$ etidronate. ( $n$ $=6$ in each group; $\mathrm{cpm}={ }^{3} \mathrm{H} \mathrm{cpm}$ in urine)

total 24-h bone resorption as assessed with $\left[{ }^{3} \mathrm{H}\right] \mathrm{TC}$ urinary excretion, and it leads to an increased calcium balance as well as a conspicuous increase in bone mass. To our knowledge, this is the first time that such an effect has been described. The decrease in bone resorption is brought about by fractionating both the solid and liquid intake. While fractionating the food blunts only the peak height of the diurnal rhythm of bone resorption, water fractionation also diminishes the nadir between the peaks. Thus, two separate mechanisms seem to operate. This view is also supported by the different kinetics of these effects. However, these two effects were not additive, suggesting that they may operate at some point through the same as yet unknown mechanism(s).

It could be argued that rats on fractionated feeding schedules are subject to increased mobility, which, in turn, would decrease bone resorption. However, we found, if anything, a tendency for a decrease in muscularly demanding activity in rats subjected to food fractionation, suggesting that the present results can hardly be explained with differences in physical activity.

In TPTX animals, no food-induced increase in bone resorption is observed. Thus, PTH and/or calcitonin appear to be critically involved in the food-induced diurnal rhythm of bone resorption, and, therefore, their diurnal profiles are presently being investigated. In TPTX rats, there is still a small diurnal rhythm of bone resorption that is, however, independent of dietary manipulations. As previously discussed, this may represent a true circadian rhythm onto which, in intact animals, a diet-induced rhythm is superimposed (4). Whether this PTHand calcitonin-independent rhythm of resorption is related to the recently described bone resorbing activity in rat serum remains to be established (11).

The mechanism(s) by which food intake stimulates bone resorption is not yet understood. The possibility that, since food intake is followed by an increase in bone formation, the calcium requirement for mineralization may trigger bone resorption was found to be unlikely. Indeed, when the calcium requirement was reduced by inducing an inhibition of mineralization with high doses of etidronate, the fractional increase of bone resorption occurring after food ingestion was not affected.

Exogenous calcitonin abolished almost exclusively the increase of bone resorption observed after food administration. The effect occurred within hours and was reversible after discontinuation of treatment. This result strongly suggests that the increase of bone resorption observed after food administration is an osteoclast-mediated event. The effect is dependent upon the time of administration of the hormone with respect to the food intake, an optimal effect being obtained if calcitonin is given $3 \mathrm{~h}$ beforehand. This could be relevant for the administration of calcitonin in humans. Future work will be required to establish whether endogenous calcitonin plays a physiological role in the modulation of the diurnal rhythm of bone resorption. Recently, a protective effect of endogenous calcitonin against PTH-stimulated bone resorption has been found (12).

The effect of calcitonin contrasts with the effect of another type of inhibitor of bone resorption, the bisphosphonates. Alendronate affects $24-\mathrm{h}$ bone resorption by decreasing the nadir of the peaks but not their fractional amplitude, confirming previous results (4). Therefore, some fundamental differences in the mechanism of action of these two most powerful inhibitors of bone resorption are present. Possibly the fact that calcitonin acts directly on osteoclasts while, according to recent results, bisphosphonates act also through the mediation of osteoblasts on bone resorption could be relevant (13). The presence of two mechanisms is also supported by the finding that effects of the bisphosphonate and calcitonin are additive, as indicated in Fig. $7 \mathrm{~b}$. Such an additive effect of calcitonin and the bisphosphonate etidronate has been observed in humans afflicted with Paget's disease (14) and may be relevant in cases when hypercalcemia has to be corrected rapidly. However, our results contradict some results obtained in the rat where resorption was assessed by measuring $\left[{ }^{3} \mathrm{H}\right] \mathrm{TC}$ in $24-\mathrm{h}$ urine and where no additive effects of calcitonin and a bisphosphonate were found (15). A different methodology in these experiments may have precluded the detection of an additive effect. Indeed, in that method, the $\left[{ }^{3} \mathrm{H}\right] \mathrm{TC}$ labeling with high activity was started only $12 \mathrm{~d}$ before the urine collection and pursued for $10 \mathrm{~d}$, so that, since primary spongiosa in growing rats has a life span of only about $5 \mathrm{~d}(16)$, some calcified cartilage turnover will be assessed. If calcitonin inhibits the resorption of calcified cartilage less efficiently than older bone, the discrepancy with our results could be explained.

It is not yet known whether the effects of food and water fractionation on bone resorption are also present in humans. A diurnal fluctuation in bone resorption is known to be present in 
adult humans, indicated by an increased urinary excretion of the markers of bone resorption, hydroxyproline (17), and pyridinium cross-links $(18,19,20)$ during the night. Whether in these subjects the main meal was in the evening and the fluctuation was therefore at least partially food induced is not known.

If a food-induced bone resorption also occurs in humans, its modulation by an increased meal frequency might possibly be used to decrease bone resorption and increase bone balance. This might be of use both in adolescents to increase bone mass and in the elderly to diminish bone loss, and would represent a new way to prevent the development of osteoporosis. Furthermore, the existence of an optimal time for the administration of calcitonin may also represent a novel strategy to optimize the benefit from this drug.

\section{Acknowledgments}

We thank A. Reinli, A. Lozano, B. Hoffmann, and S. Palacio for skillful technical assistance, and $O$. Aeby for the construction of the feeding device. We are grateful to Dr. A. K. Dixon (Sandoz Research Institute, Berne, Switzerland) for sharing his knowledge of ethopharmacology with us, and to T. Hostettler for evaluating the video tapes. We also thank I. Ryf for correcting the English typescript, and J. Sigrist and A. Reinli for their help with the illustrations.

This investigation was supported in part by the Swiss National Science Foundation (32-9520.88 and 32-31'272.91) and by Nestec Ltd., (Lausanne, Switzerland).

\section{References}

1. Lindsay, R., and F. Cosman. 1992. Primary osteoporosis. In Disorders of Bone and Mineral Metabolism. F. L. Coe and M. J. Favus, editors. Raven Press, New York. 831-888.

2. Consensus Development Conference. 1993. Diagnosis, prophylaxis and treatment of osteoporosis. Am. J. Med. 94:646-650.

3. Riggs, B. L., and L. J. Melton III. 1992. The prevention and treatment of osteoporosis. N. Engl. J. Med. 327:620-627.

4. Mühlbauer, R. C., and H. Fleisch. 1990. A method for continual monitoring of bone resorption in rats: evidence for a diurnal rhythm. Am. J. Physiol. 259:R679-R689.

5. Klein, L., and K. Van Jackman. 1976. Assay of bone resorption in vivo with ${ }^{3}$ H-Tetracycline. Calcif. Tissue Res. 20:275-290.

6. Dixon, A. K., H. U. Fisch, and K. H. McAllister. 1990. Ethopharmacology: a biological approach to the study of drug-induced changes in behavior. Adv. Study Behav. 19:171-204.

7. Dixon, A. K., H. U. Fisch, C. Huber, and A. Walser. 1989. Ethological studies in animals and man: their use in psychiatry. Pharmacopsychiatry. 22(Suppl. 1):44-50.

8. Hefti, E., U. Trechsel, H. Rüfenacht, and H. Fleisch. 1980. Use of dermestid beetles for cleaning bones. Calcif. Tissue Int. 31:45-47.

9. Mühlbauer, R. C., F. Bauss, R. Schenk, M. Janner, E. Bosies, K. Strein, and H. Fleisch. 1991. BM 21.0955, a potent new bisphosphonate to inhibit bone resorption. J. Bone Miner. Res. 6:1003-1011.

10. Mühlbauer, R. C. 1994. Biochemical assessment of bone metabolism in rodents. In Sex Steroids and Bone. R. Ziegler, J. Pfeilschifter, and M. Bräutigam, editors. Springer-Verlag, Berlin, Heidelberg, New York. 191-202.

11. Shinoda, H., and P. H. Stern. 1992. Diurnal rhythms in Ca transfer into bone, $\mathrm{Ca}$ release from bone, and bone resorbing activity in serum of rats. Am. J. Physiol. 262:R235-R240.

12. Yamamoto, M., J. G. Seedor, G. A. Rodan, and R. Balena. 1993. Endogenous calcitonin reduces PTH-induced bone resorption in rats. J. Bone Miner. Res. 8(Suppl. 1):S191. (Abstr.)

13. Sahni, M., H. L. Guenther, H. Fleisch, P. Collin, and T. J. Martin. 1993. Bisphosphonates act on rat bone resorption through the mediation of osteoblasts. J. Clin. Invest. 91:2004-2011.

14. Hosking, D. J., and O. L. M. Bijvoet. 1976. Combined diphosphonate and calcitonin therapy for Paget's Disease of bone. Calcif. Tissue Res. 21 (Suppl.):321-326.

15. Sjögren, S., K. Rydström, and B. Wallmark. 1991. The effects of clodronate and salmon calcitonin on daily rat bone resorption. J. Bone Miner. Res. 6(Suppl. 1):S175. (Abstr.)

16. Kimmel, D. B., and W. S. S. Jee. 1980. Bone cell kinetics during longitudinal bone growth in the rat. Calcif. Tissue Int. 32:123-133.

17. Radom, S., M. Zulawski, and E. Dahlig. 1972. Circadian rhythm of total urinary hydroxyproline excretion and 3-H hydroxyproline test. Clin. Chim. Acta. 39:277-278.

18. Kamel, S., M. Brazier, G. Desmet, C. Picard, I. Mennecier, and J. Sebert. 1992. High-performance liquid chromatographic determination of 3-hydroxy-pyridinium derivatives as new markers of bone resorption. J. Chromatogr. 574:255260.

19. Eastell, R., M. S. Calvo, M. F. Burritt, K. P. Offord, R. G. G. Russell, and B. L. Riggs. 1992. Abnormalities in circadian patterns of bone resorption and renal calcium conservation in type I osteoporosis. J. Clin. Endocrinol. \& Metab. 74:487-494.

20. Schlemmer, A., C. Hassager, S. B. Jensen, and C. Christiansen. 1992. Marked diurnal variation in urinary excretion of pyridinium cross-links in premenopausal women. J. Clin. Endocrinol. \& Metab. 74:476-480. 